\title{
Relation between the celestial tide-generating stress and the temperature variations of the Abruzzo $M=6.3$ Earthquake in April 2009
}

\author{
W. Y. Ma ${ }^{1,2}$, H. Wang ${ }^{1}$, F. S. Li $^{1}$, and W. M. Ma ${ }^{3}$ \\ ${ }^{1}$ Institute of GIS/RS/GPS \& Subsidence Research, China University Mining \& Technology, Beijing, China \\ ${ }^{2}$ College of Geography and Environmental Sciences, Zhejiang Normal University, Jinhua, China \\ ${ }^{3}$ College of Information Technology, Beijing Normal University, Zhuhai Campus, Zhuhai, China
}

Correspondence to: W. Y. Ma (weiyuma@163.com)

Received: 19 August 2011 - Revised: 26 January 2012 - Accepted: 2 February 2012 - Published: 30 March 2012

\begin{abstract}
The temperature variations caused by additive tectonic stress has been studied to explain its relationship with the seismic fault sliding of the Abruzzo $M=6.3$ Earthquake in April 2009. According to the periodic changes of the additive tectonic stress caused by the celestial tidegenerating force, the temperature variations before and after the earthquake have been analyzed based on the temperature data from National Centers for Environmental Prediction (NCEP). The figures of temperature variations clearly show that the abnormal increasing of the temperature has resulted from seismic fault sliding. Based on this method, it is possible to forewarn short-impending earthquakes.
\end{abstract}

\section{Introduction}

The thermal anomalies around the place and the time of an earthquake have been extensively discussed. As said in Lisi et al. (2009), these anomalies may arise from the increase in green-house gas (such as $\mathrm{CO}_{2}, \mathrm{CH}_{4}$ ) emission rates, the modification of the ground water regime, the increase of convective heat flux or more complex phenomena caused by the other pre-seismic effects (Tronin, 2006). When viewed from the sources of thermal energy during the process of an earthquake, under the aggravated stress of the Earth's crust the generating mechanical strain energy and other physical, chemical energy is generated, and most of this will be transformed into thermal energy with infra-red radiation mode and released through various channels. Therefore, the measurement of infra-red anomaly of earth shock from high-altitude satellites or earth surface may provide a comprehensive reflection of various thermal energy sources (Ma, 2006). The transient thermal rise in and around epicenter areas shows us a useful way to study the activities of seismic tectonics by the TIR (Thermal Infra-Red) of temperature (Ouzounov et al., 2004). However, because infra-red waves can hardly penetrate clouds, when there are lots of clouds over the epicenter area, the TIR of temperature cannot be surveyed correctly by remote sensing technology. In addition, the mechanism of temperature variations is so complicated that the selection of different benchmark values of temperature may get different results for TIR anomalies. In the paper of Yang et al. (2010), a subtraction method is used. For example, yesterday's temperature at 18:00 UTC is subtracted from today's temperature at 18:00 UTC, and in this way the time-series of differences of temperatures are worked out and plotted in a figure which is used to pick up the day of TIR anomaly. To further precisely detect the TIR anomalies, the meteorology temperature data collected from 700 weather stations were used by Yang et al. (2010) as complementarities to obtain the relatively exact differences of temperature of an Earth surface. Such methods may require much effort to collect and process data. In the paper of Zhang et al. (2010), a wavelet transform method is used to process the brightness temperature data which can be obtained through using the thermal radiation data from the TIR satellite remote sensing data. For this method, the different wavelet transform criterion functions and window sizes of the Fourier Transformation used may obtain different TIR anomalies. Another approach named RST (Robust Satellite Technique), which is based on a statistical definition of "TIR anomalies", is introduced and used in several earthquakes studies 
(Tramutoli, 2005, 2007; Lisi et al., 2010). TIR anomalies can be identified as deviations from those "normal" conditions, using a specific index, RETIRA (Robust Estimator of TIR Anomalies, Filizzola et al., 2004; Tramutoli et al., 2009), and computed on the related images. In addition, the RST has always been carried out by using a validation/confutation approach (Tramutoli, 2007; Lisi et al., 2010; Lovallo et al., 2007; Marchese et al., 2006). However, as showed in Lisi et al. (2010), Marchese et al. (2006), and Lovallo et al. (2007) , although the RST approach has been well applied to the Abruzzo $M=6.3$ Earthquake and gives a convincing result, it relies too much on the availability of historical data (the Advanced Very High Resolution Radiometer (AVHRR) images for $15 \mathrm{yr}$ ). So it maybe not very appropriate to be used in studying other different earthquake regions with less historical data. Furthermore, the use of RST will be affected by some not ideal circumstances, such as occasional warming, day-to-day and/or year-to-year climatological changes, and/or season time-drifts. The availability of historical data for many years, the decision of researchers, the choice of different data-sets, and other non-objective factors may bring out different results.

In this paper, we introduce the model of additive tectonic stress, which comes from the celestial, tide-generating force to analyze the temperature anomalies of the Abruzzo $M=6.3$ Earthquake. In Sect. 3, we give a more detailed explanation of the model and in Sect. 4, the temperature anomalies are drawn in images to explain their relationship to seismic fault sliding. The model does not rely on large historical data and the result is more clearly to understand.

\section{The case of the 6 April 2009 Abruzzo earthquake}

The earthquake occurred in the Abruzzi region (Central Italy). Its epicenter is at $42.334^{\circ} \mathrm{N}$ and $13.334^{\circ} \mathrm{E}$ where is near L'Aquila, the capital of Abruzzo. The main shock occurred at 03:32 local time (01:32 UTC) on 6 April 2009, and was rated $M=6.3$ on the moment magnitude scale. There have been many shocks since December 2008 and some of them with local magnitude 4.0 or higher. For example, on 8 March $2009\left(41.55^{\circ} \mathrm{N} / 18.55^{\circ} \mathrm{E}\right)$, with $M_{\mathrm{L}}=$ 5.2, on 7 April $2009\left(42.62^{\circ} \mathrm{N} / 13.17^{\circ} \mathrm{E}\right)$, with $M_{\mathrm{L}}=5.4$, on 9 April 2009 , with $M_{\mathrm{L}}=5.5$ at $\left(42.64^{\circ} \mathrm{N} / 13.37^{\circ} \mathrm{E}\right)$, on 10 April $2009\left(42.80^{\circ} \mathrm{N} / 13.02^{\circ} \mathrm{E}\right)$, with $M_{\mathrm{L}}=5.3$ (http://data.earthquake.cn/data/).

The earthquake occurred as a result of normal faulting on a NW-SE oriented structure in the central Apennines where a mountain belt runs from the Gulf of Taranto in the South to the southern edge of the Po basin in northern Italy (Chiarabba et al., 2009; Telesca, 2010). The central part of the Apennines has been characterized by extensional tectonics since the Pliocene epoch (i.e. about the last 5 million years), with most of the active faults normal in type and NW-SE trending (Akinci et al., 2009). The extension is due to the back-arc basin in the Tyrrhenian Sea opening faster than the African Plate collides with the Eurasian Plate (USGS, 2009). Geologically, the Apennines are largely an accretionary wedge formed as a consequence of subduction. The region is tectonically and geologically complex, involving both subduction of the Adria micro-plate beneath the Apennines from east to west, continental collision between the Eurasian and African plates building the Alpine mountain belt further to the north and the opening of the Tyrrhenian basin to the west. The evolution of this system has caused the expression of all different tectonic styles acting at the same time in a broad region surrounding Italy and the central Mediterranean. The 6 April 2009 earthquake is related to normal faulting and the east-west extensional tectonics that dominate along the entire Apennine belt, primarily a response to the Tyrrhenian basin opening faster than the compression between the Eurasian and African plates.

\section{The change of additive tectonic stress from the celestial tide-generating force for the Abruzzo Earthquake in April 2009}

The Earth is not an isolated celestial body. In its outer space, there are the Sun, the Moon and the other celestial bodies. So its running is affected by various, external, cosmic, environmental factors, in which the celestial bodies' tide is a major one (Heaton, 1975; Ma et al., 2008; Kalnay et al., 1996). The gravity from celestial bodies such as the Sun and the Moon to the geocentric or any point within the Earth is defined as the Celestial Tide-generating Force (in this article, abbreviated as CTF). A clear correlation between the astronomical tidegenerating force on the Earth and the earthquake occurrence had already been successfully verified by Tanaka et al. (2002) and Cochran et al. (2004) with their carefully examining global earthquake data. Furthermore, because an earthquake is a kind of mechanical movement while a CTF can be considered as one of the possible momentum sources to trigger the activities of seismogenic structure. In this paper, we try to analyze the temperature anomalies of the Abruzzo $M=6.3$ Earthquake through the periodic variation effect of the CTF on the fault plane. The calculation of tectonic stress from the CTF is as follows.

The tidal tectonic stress components that come from the Moon and the Sun at the focus of an earthquake in the spherical coordinate system $(r, \theta, \phi)$ is calculated. The use of $(r, \theta, \phi)$ to denote, respectively, radial distance, inclination (or elevation), and azimuth. The calculation is according to Kelvin's method, which gives the values of tidal tectonic stress components in the elastic spherical model and does not consider the case of self-weight stress. The formula for calculating the stress of $n$-order difference tidal force is $(\mathrm{Wu}$, 1997): 


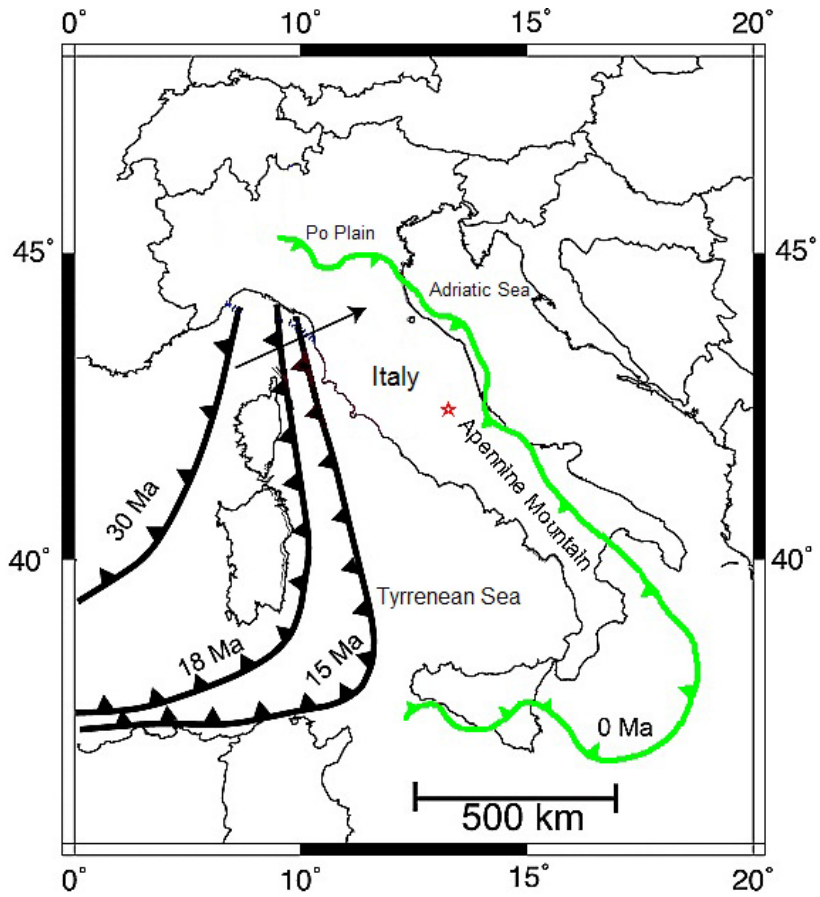

Fig. 1. The location and the main plates of the Abruzzo $M=6.3$ Earthquake on 6 April 2009. Note: the $\forall$ is the epicenter, the $r$ is the main thrust fault. (Benoit et al., 2011).

$$
\left\{\begin{aligned}
\sigma_{r r}= & \frac{n^{2}}{m} \rho\left\{(n+2) \lambda+(n+1) \mu\left[\frac{R^{2}}{r^{2}}-1\right]\right\} W_{m} \\
\sigma_{\theta \theta}= & \frac{n^{2}}{m} \rho\left\{\left[\frac{(n+2) \lambda+(n+1) \mu}{(n-1)}-(\lambda+\mu)\right] W_{m}\right. \\
& \left.+\left[\frac{R^{2}[(n+2) \lambda+(n+1) \mu]}{r^{2}(n-1)}-\frac{(n+3) \lambda+(n+2) \mu}{n^{2}}\right]\right\} \frac{\partial^{2} W_{m}}{\partial \theta^{2}} \\
\sigma_{\lambda \lambda}= & \frac{n^{2}}{m} \rho\left\{\left[\frac{(n+2) \lambda+(n+1) \mu}{(n-1)}-(\lambda+\mu)\right] W_{m}\right. \\
& \left.+\left[\frac{R^{2}[(n+2) \lambda+(n+1) \mu]}{r^{2} n(n-1)}-\frac{(n+3) \lambda+(n+2) \mu}{n^{2}}\right]\right\} \cot \theta \frac{\partial W_{m}}{\partial \theta} \\
\sigma_{r \theta}= & \sigma_{\theta r}=\frac{n^{2}[(n+2) \lambda+(n+1) \mu]}{2 m} \rho\left\{\left[\frac{R^{2}}{r^{2}}-1\right]\right\} \frac{\partial W_{m}}{\partial \theta} \\
\sigma_{r \varphi}= & \sigma_{\varphi r}=0 \\
\sigma_{\varphi \theta}= & \sigma_{\theta \varphi}=0
\end{aligned}\right.
$$

In Eq. (1), $\sigma_{r r}, \sigma_{\theta \theta}$ and $\sigma_{\varphi \varphi}$ are the normal stress components, $\sigma_{r \theta}, \sigma_{r \varphi}$ and $\sigma_{\theta \varphi}$ are the shear stress components in the spherical coordinate system $(r, \theta, \varphi) ; R$ is the average radius of the earth; $\lambda$ and $\mu$ are the Lame constants; $W_{m}$ is the $n$-order derivative of the tide-generating potential. As for the Moon, the normal stress and the shear stress components are calculated with $n=2$ and $n=3$, respectively and then sum them up. As for the Sun, we calculate them only with $n=2$; $\theta$ is the geocentric zenith distance from the Moon or the Sun to the point which calculated with.

Second, the tidal stress components from the spherical coordinate system $(r, \theta, \varphi)$ is changed to the rectangular coordinate system $(\mathrm{X}, \mathrm{Y}, \mathrm{Z})$. The use of $(\mathrm{X}, \mathrm{Y}, \mathrm{Z})$ to denote, respectively, South, East, and Up directions. The converted formula is:

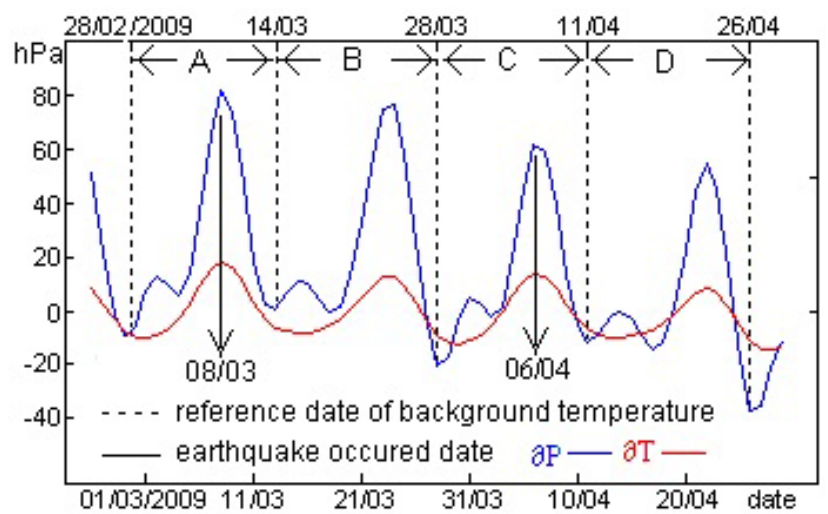

Fig. 2. The periodic changes of $\partial \mathrm{P}$ and $\partial \mathrm{T}$ according to the ATSCTF model for the Abruzzo Earthquake in April 2009.

$$
\begin{aligned}
& \left|\begin{array}{lll}
\sigma_{\mathrm{xx}} & \sigma_{\mathrm{xy}} & \sigma_{\mathrm{xz}} \\
\sigma_{\mathrm{yx}} & \sigma_{\mathrm{yy}} & \sigma_{\mathrm{xz}} \\
\sigma_{\mathrm{zx}} & \sigma_{\mathrm{zy}} & \sigma_{\mathrm{zz}}
\end{array}\right|= \\
& \left|\begin{array}{ccc}
\sigma_{\theta \theta} \cos ^{2} A+\sigma_{\varphi \varphi} \sin ^{2} A & \left(\sigma_{\varphi \varphi}-\sigma_{\theta \theta}\right) \sin A \cos A & \sigma_{\theta r} \cos A \\
\left(\sigma_{\varphi \varphi}-\sigma_{\theta \theta}\right) \sin A \cos A & \sigma_{\theta \theta} \sin ^{2} A+\sigma_{\varphi \varphi} \cos ^{2} A & -\sigma_{\theta r} \sin A \\
\sigma_{r \theta} \cos A & -\sigma_{r \theta} \sin A & \sigma_{r r}
\end{array}\right|
\end{aligned}
$$

In Eq. (2), $A$ is the azimuth of the Sun or the Moon.

And then, we sum up the tidal stress caused by the Sun and the Moon together and work out the total tidal stress on the focus of an earthquake exerted by the Moon and the Sun.

Third, the main seismic stress axis coordinate system $(\mathrm{P}, \mathrm{T}, \mathrm{N})$ is established, and the total tidal stress is changed from the rectangular coordinate system $(\mathrm{X}, \mathrm{Y}, \mathrm{Z})$ to this new coordinate system. The use of $(\mathrm{P}, \mathrm{T}, \mathrm{N})$ to denote, respectively, Pressure, Tension, and Normal vectors. Then we decompose the total tidal stress on the focus of an earthquake along the main Pressure axis ( $\mathrm{P}$-axis) and along the main Tension axis (T-axis) to obtain the additional tidal stress.

$$
\left\{\begin{array}{c}
\partial_{\mathrm{P}}=\sigma_{\mathrm{xx}} \mathrm{B}_{\mathrm{PX}}^{2}+\sigma_{\mathrm{yy}} \mathrm{B}_{\mathrm{PY}}^{2}+\sigma_{\mathrm{zz}} \mathrm{B}_{\mathrm{PZ}}^{2}+2 \sigma_{\mathrm{xy}} \mathrm{B}_{\mathrm{PX}} \mathrm{B}_{\mathrm{PY}}+2 \sigma_{\mathrm{yz}} \\
\mathrm{B}_{\mathrm{PY}} \mathrm{B}_{\mathrm{PZ}}+2 \sigma_{\mathrm{zx}} \mathrm{B}_{\mathrm{PZ}} \mathrm{B}_{\mathrm{PX}} \\
\partial_{\mathrm{T}}=\sigma_{\mathrm{xx}} \mathrm{B}_{\mathrm{TX}}^{2}+\sigma_{\mathrm{yy}} \mathrm{B}_{\mathrm{TY}}^{2}+\sigma_{\mathrm{zz}} \mathrm{B}_{\mathrm{TZ}}^{2}+2 \sigma_{\mathrm{xy}} \mathrm{B}_{\mathrm{TX}} \mathrm{B}_{\mathrm{TY}}+2 \sigma_{\mathrm{yz}} \\
\mathrm{B}_{\mathrm{TY}} \mathrm{B}_{\mathrm{TZ}}+2 \sigma_{\mathrm{zx}} \mathrm{B}_{\mathrm{TZ}} \mathrm{B}_{\mathrm{TX}}
\end{array}\right.
$$

The parameters in the above formula are worked out by:

$$
\left\{\begin{array}{l}
\mathrm{B}_{\mathrm{PX}}=-\sin H \cos Q \sin V-\sin Q \cos V \\
\mathrm{~B}_{\mathrm{PY}}=-\sin H \sin Q \sin V+\cos Q \cos V \\
\mathrm{~B}_{\mathrm{PZ}}=\sin V \cos H \\
\mathrm{~B}_{\mathrm{TX}}=-\sin H \cos Q \cos V+\sin Q \sin V \\
\mathrm{~B}_{\mathrm{TY}}=-\sin H \sin Q \cos V-\cos Q \sin V \\
\mathrm{~B}_{\mathrm{TY}}=\cos H \cos V
\end{array}\right.
$$

In Eq. (4), $H, V$ and $Q$ are the rotation angles which can be obtained according to the formulas in the book of Zhu (1988). 


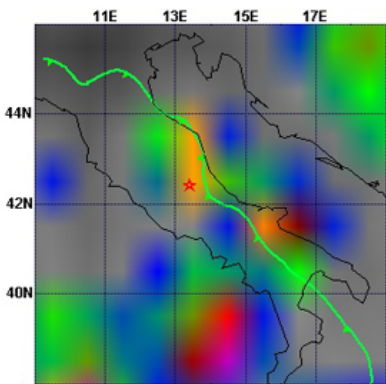

$29 / 03 / 2004$

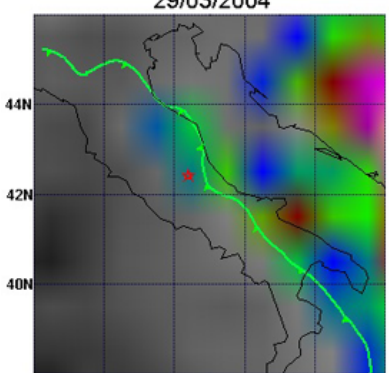

$02 / 04 / 2004$

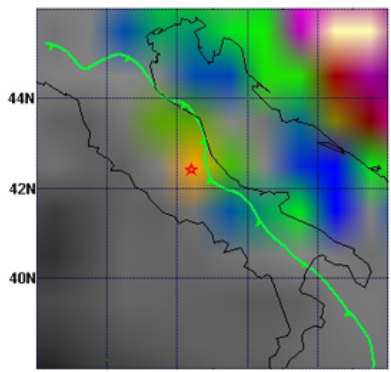

$06 / 04 / 2004$

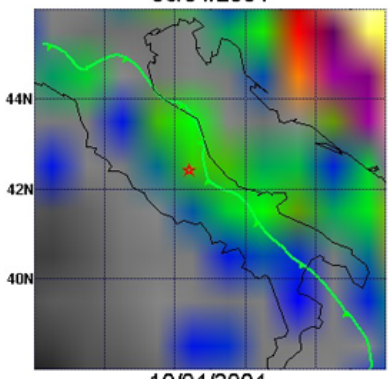

$10 / 04 / 2004$

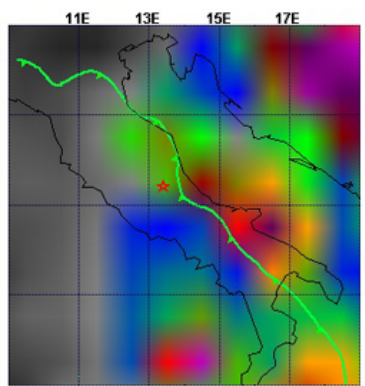

$30 / 03 / 2004$

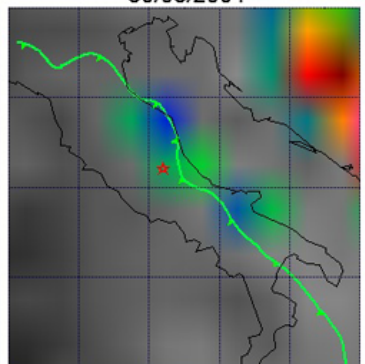

$03 / 04 / 2004$

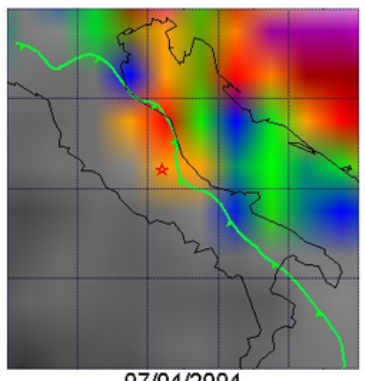

$07 / 04 / 2004$

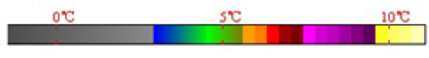

main thrust fault

* epicenter

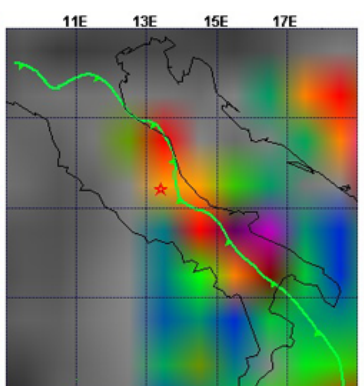

$31 / 03 / 2004$

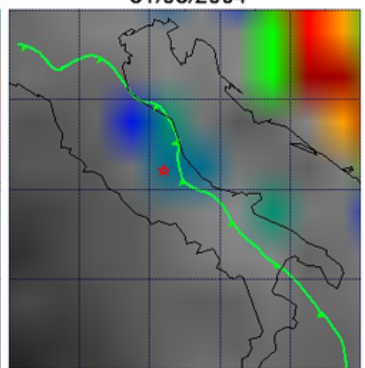

04/04/2004

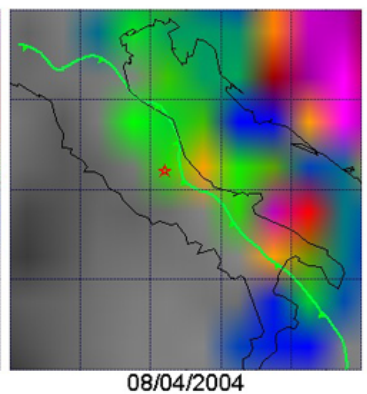

$08 / 04 / 2004$

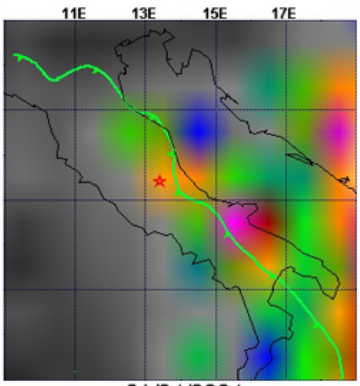

01/04/2004

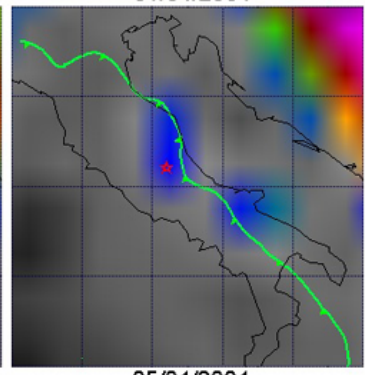

$05 / 04 / 2004$

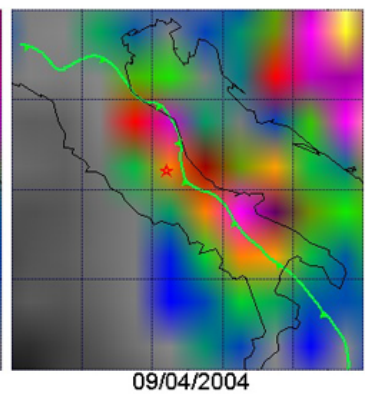

Fig. 3. Spatial-time evolution of the temperature changing based on the NCEP data (all at 00:00 UTC) for the Abruzzo Earthquake in April 2009.

Thus, we introduce the model of the Additive Tectonic Stress from Celestial Tide-generating Force (in this article abbreviated as ATSCTF), which is defined as the additional tidal stress (i.e. $\partial \mathrm{P}$ and $\partial \mathrm{T}$ ) at the epicenter along the main pressure (P-axis) and tension stress (T-axis) caused by the CTF of the Sun and the Moon.

There are three ways by which the additive tectonic stress can aggravate the sliding of seismic fault (Ma et al., 2008):

1. Stress increases. The compressive stress and the shear stress increase in the fault plane, the fault tension increases. Until the stresses reach the critical state and then trigger an earthquake. The earthquake occurs at both tops of $\partial \mathrm{P}$ and $\partial \mathrm{T}$;

2. Stress decreases. The compressive stress and the shear stress decrease in the fault plane, the friction decreases in the fault plane. Until the stresses reach the critical state and then trigger an earthquake. The earthquake occurs at the both bottoms of $\partial \mathrm{P}$ and $\partial \mathrm{T}$;

3. Stress sometimes increases and sometimes decreases. The unilateral stress changes in the fault plane and breaks the balance of the fault plane. The energy 

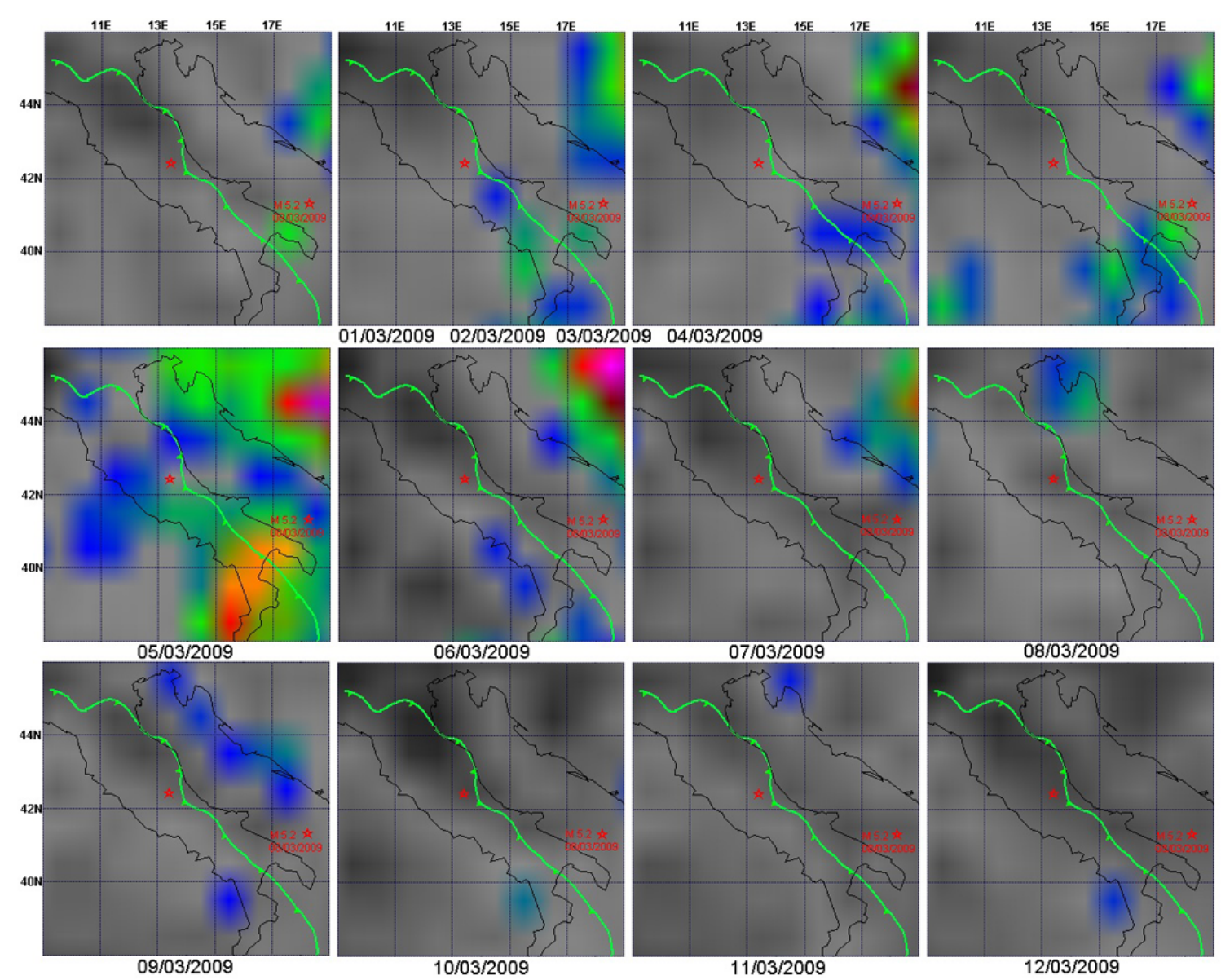

Fig. 4. Spatial-time evolution of the temperature changing based on the NCEP data (all at 00:00 UTC) in the cycle "A".

already stored in the fault plane releases and triggers the earthquake. The earthquake occurs at the time when $\partial \mathrm{P}$ and $\partial \mathrm{T}$, one is in the top, the other is in the bottom;

These three ways respectively correspond to the normal fault (Ma et al., 2007), the reverse fault (Ma et al., 2008), and the strike-slip fault (Ma et al., 2011).

Figure 2 shows the changing of $\partial \mathrm{P}$ and $\partial \mathrm{T}$ of the Abruzzo Earthquake from 27 February 2009 to 26 March 2009. The blue line indicates the $\partial \mathrm{P}$ and the red one indicates the $\partial \mathrm{T}$. It shows that the periodic changes of additive tectonic stress come from the CTF and that there are four cycles which are denoted as "A", "B", "C" and "D", respectively.

The earthquake occurred at the both tops of $\partial \mathrm{P}$ and $\partial \mathrm{T}$ in the cycle "C", so the way the additive tectonic stress acted on it belongs to "the stress increasing" type. That is to say, the stress increased not only the positive stress of the fault plane, but also the rupture-slide intensity of the fault plane, then accelerated the status of fault stress to reach the critical point and promoted the fault sliding. On the other side, the earthquake occurred not as usually expected at the time of its additive tectonic stress turning point (on $28 \mathrm{March}$ ). This implies that the accelerate action of the additive tectonic stress successively promotes the fault sliding, and the instantaneous change of the additive tectonic stress does not trigger violent shock at once but when the tectonic stress reaches its critical broken point.

The earthquake with $M_{\mathrm{L}}=5.2$ on 8 March $\left(41.55^{\circ} \mathrm{N} / 18.55^{\circ} \mathrm{E}\right)$ occurred at the high value of the tidal tectonic stress. It is similar to the Abruzzo main earthquake $(M=6.3)$, for these two earthquakes are dominated by the same tectonic features.

\section{The temperature changing process of the earthquake}

The studies on the temperature abnormal rise before earthquakes (Gorny et al., 1988) and the thermal rise of rocks under stress (Wu et al., 2000) imply that the stage of tectonic moving can be detected by the temperature abnormal rise over the Earth surface. This gives us an inspiration to observe the state of tectonic stress. Then, the purpose of our study is to detect the effectiveness of the CTF being as one of the precursory signals for temperature variation of the Abruzzo Earthquake and then to discover the mechanism behind it. In this paper, the ATSCTF model is proposed as a 

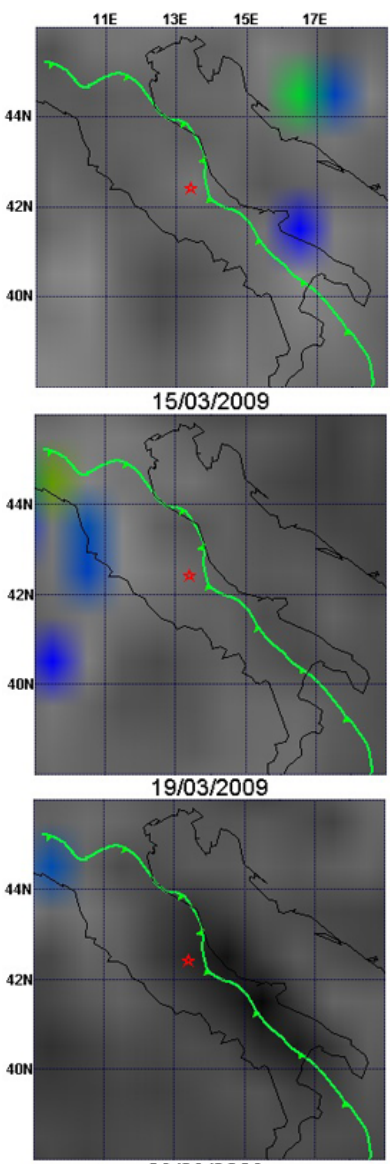

$23 / 03 / 2009$

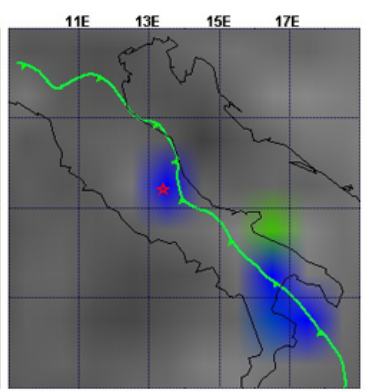

$16 / 03 / 2009$
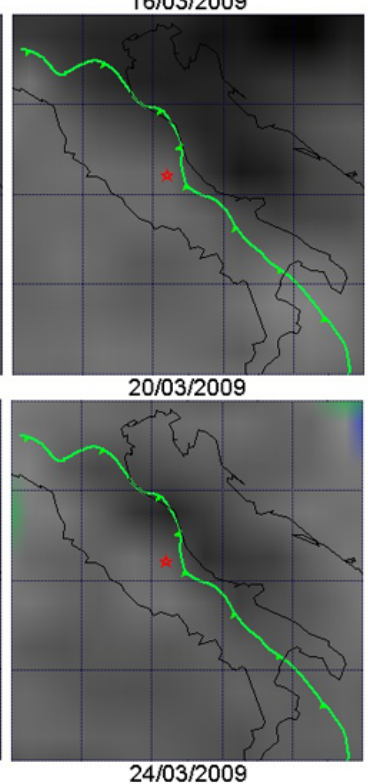

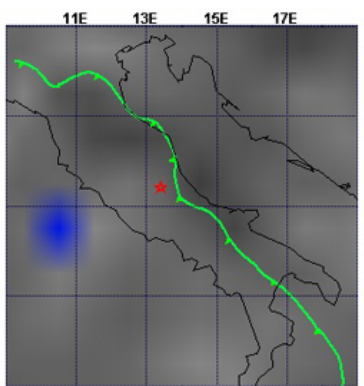

$17 / 03 / 2009$
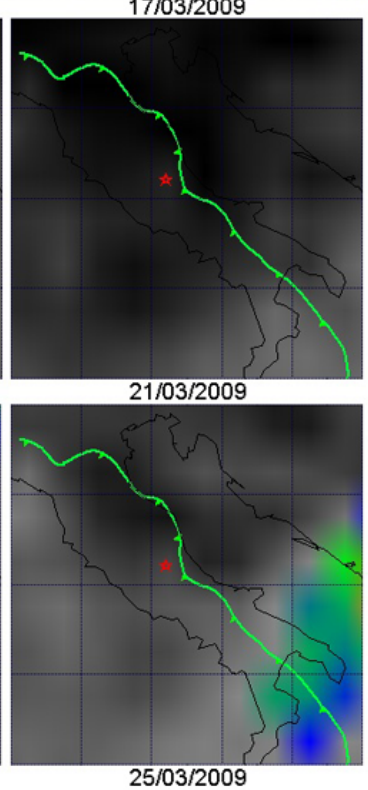

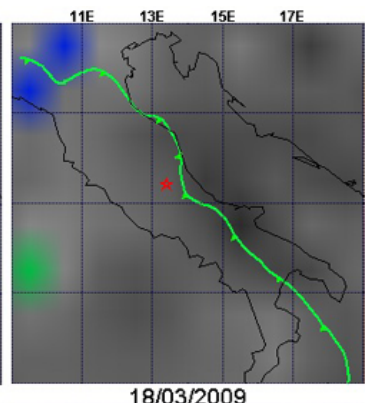

$18 / 03 / 2009$

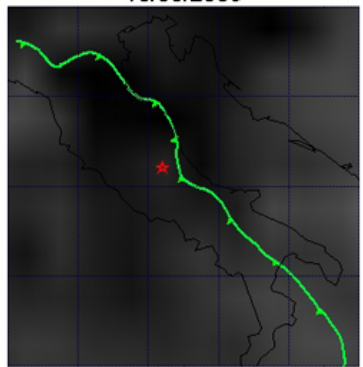

$22 / 03 / 2009$

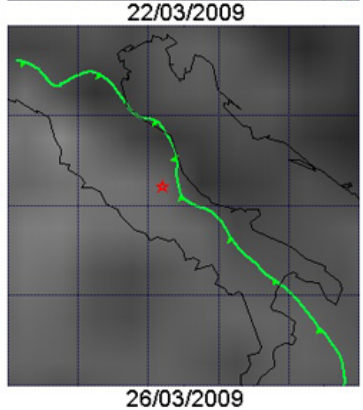

Fig. 5. Spatial-time evolution of the temperature changing based on the NCEP data (all at 00:00 UTC) in the cycle "B".

method to pick out the temperature benchmark value for the seismically active region, and then use it to detect and monitor thermal anomalies relating to the earthquake.

Based on the ATSCTF model as showed in Fig. 2, the data from NCEP is used to analyze the temperature abnormal variations during the Abruzzo $M=6.3$ earthquake. The temperature benchmark value is set to the number at 00:00 UTC on 28 March 2009 (before the earthquake) at $1000 \mathrm{hPa}\left(1 \mathrm{hPa}=100 \mathrm{~N} / \mathrm{m}^{2}\right)$ when the values of $\partial \mathrm{P}$ and $\partial \mathrm{T}$ of the tidal tectonic stress are the minimum according to the ATSCTF model. Then the temperature values from $29 \mathrm{March}$ to 10 April are subtracted from this temperature benchmark value at the same time as 00:00 UTC, the same altitude as $1000 \mathrm{hPa}$ and the same region. Thus we obtained a series of temperature variations which are visually showed in Fig. 3.

It is very clearly showed in Fig. 3 that there were some significantly abnormal temperature rises from 29 March to 10 April. On 29 March, the temperature increased about $3 \sim 6^{\circ}$ in most of the area (blue and green areas in Fig. 3), especially in the south-west, the north-east and the middle of the future epicenter area; On March 30, the temperature increased significantly in the north-east and the south-east of the future epicenter area. The temperature increased about $9^{\circ}$ in the north-east area and abut $7^{\circ}$ in the south-east area. The temperature increasing began move from the south area to the east area. From 2 April to 5 April, the temperature increasing gradually weakened and it went its way mainly along the NW-SE geological structure in the central Apennines. The north-east area still had a sustained temperature increasing but its area began to shrink. The temperature increasing also began vanish in the south area. On 6 April, the temperature increased about $9^{\circ}$ in the north-east area and the main earth shock occurred. The area of temperature rise began to expand in the north-east area again. On 7 April, the earthquake was over but the temperature did not decrease at once. On 8 April, the area of temperature rise mainly appeared in the east of the epicenter. On 9 April, the temperature increased about $6^{\circ}$ in the epicenter area and another aftershock occurred $\left(M_{\mathrm{L}}=5.5\right)$. From 10 April, the temperature increasing gradually weakened again. For the other three cycles "A", "B" and " $D$ " in ATSCTF model, there are no such significantly abnormal temperature rises as in the cycle " $\mathrm{C}$ " (As showed in Figs. 4, 5 and 6, respectively). This may because there were no severe earthquakes occurred. As showed in Fig. 4, there was a sustained temperature rise since 1 March and reached the peak on 5 March. This temperature rise related to a shock 

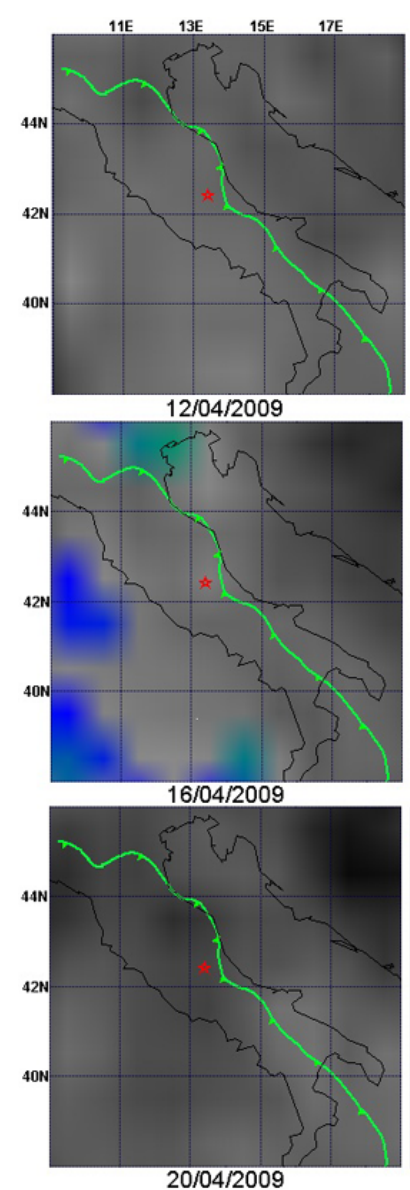

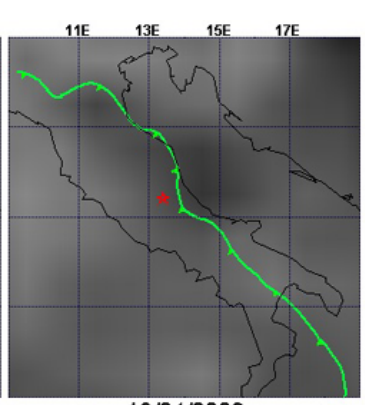

$13 / 04 / 2009$
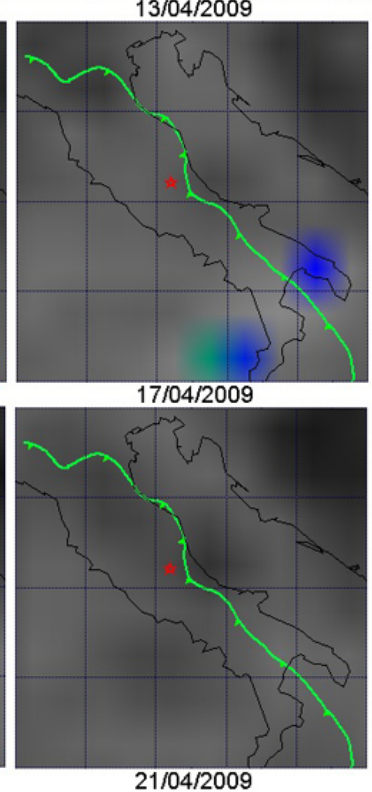
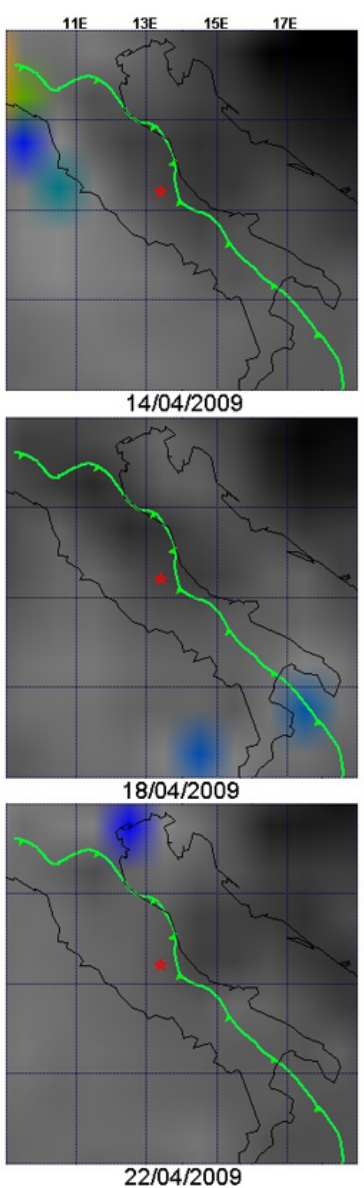
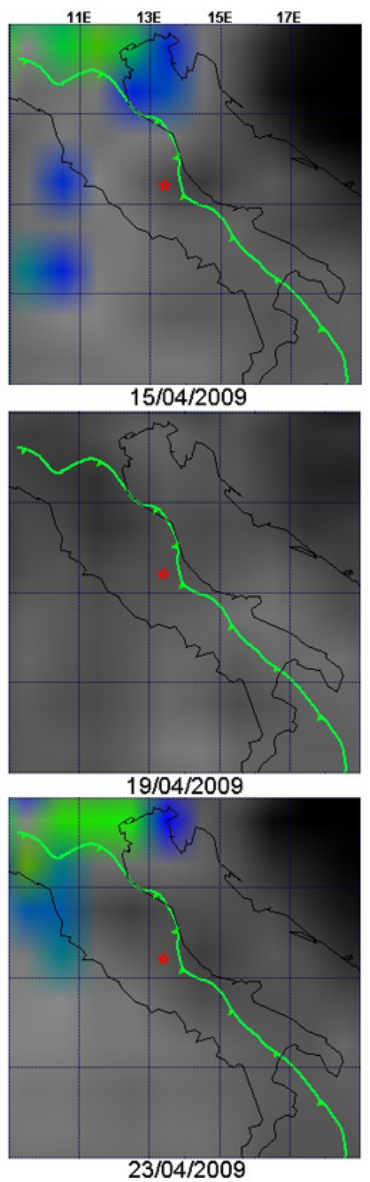

Fig. 6. Spatial-time evolution of the temperature changing based on the NCEP data (all at 00:00 UTC) in the cycle "D".

occurred at Adriatic Sea with $M_{\mathrm{L}}=5.2\left(41.55^{\circ} \mathrm{N} / 18.55^{\circ} \mathrm{E}\right)$ on 8 March. In these figures, the temperature changing images for these days: 28 February, 14 March, 28 March and 11 April are not showed because they are chosen to set the temperature benchmark values according to the ATSCTF model.

These figures perfectly reflect the process of the earthquake and they also indicate that the CTF can't induce the earthquake directly by itself, though the decisive factor is the seismotectonic activities. The progress of the fault activities can be reflected through the changes of temperature. From the serials of temperature changing images in Fig. 3, it can be seen that the temperature rise went through such successive evolution as: initial temperature rising (on 29 March) $\rightarrow$ continued rapid rising (on $31 \mathrm{March}) \rightarrow$ reaching the peak (on 1 April) $\rightarrow$ weakening (from 2 to 5 April) $\rightarrow$ rising again (from 6 to 8 April, earthquake occurred) $\rightarrow$ reaching another peak (on 9 April, severe aftershock occurred) $\rightarrow$ weakening again (on 10 April). The successive evolution of temperature rise is consistent with the rock broken process under stress loading (Wu et al., 2006). In spatial, the process of a rock break under the extrusion of tectonic movement is as: micro-breaking $\rightarrow$ rupture strengthening $\rightarrow$ accumulating energy (the atresia of stress) $\rightarrow$ releasing energy $\rightarrow$ shaking $\rightarrow$ tranquilizing. The plate abnormal movement along the NW-SE direction is consisting with the tectonic activity and reflects the continental collision between the Eurasian and the African plates. The tectonic plates go through such a process as: splitting (on 29 March) $\rightarrow$ aggregating $\rightarrow$ linking into pieces $\rightarrow$ converging to the epicenter. This clearly reflects the fault activities under the tectonics stress. Its consistence with the temperature abnormal rise in earthquake area implies that the use of CTF to achieve the information of temperature anomalies before an earthquake is feasible.

\section{Conclusions}

Earthquake is considered as a kind of physically mechanical movement. So it can be thought that the CTF is an external factor to trigger an earthquake. In this paper, the periodic change of tectonic stress comimg from CTF is used to acquire the state of the seismic tectonics and the process of temperature abnormal rise for the Abruzzo Earthquake in April 2009. The figures of spatial-time evolution of abnormal 
temperature rise clearly and reflect the activities of the seismic fault under tectonic stress. It has been firstly introduced by the authors to explain the relationship between the additive tectonic stress and the seismic fault sliding.

There is a relationship between the tectonic stress coming from CTF and the temperature variation at $1000 \mathrm{hPa}$ over the seismic tectonics. Among the four variation cycles of the tectonic stress in the ATSCTF model, only in the cycle " $C$ ", there are sustained and significant temperature changes. These correspond to the main earthquake $(M=6.3)$ occurred in the middle cycle " $C$ " while in other cycles, there were no sustained and significant temperature changes and no big earthquakes occurred. This phenomenon may help us to identify the state of tectonic stress; it is feasible to achieve the temperature change before an earthquake with the ATSCTF model.

It is necessary to combine the study of the CTF with the study of temperature abnormal rise. This can not only explore the catastrophic events of the seismic faults under tectonic stress, but also reveal the complex process of the energy accumulating and releasing during an earthquake. The question for further research is how to determine the exact benchmark time which can be used to detect temperature change in advance of an earthquake.

Acknowledgements. We are particularly grateful to professor Wu Lixin of Beijing Normal University for his constant help, supports and encouragements to our program over the last two years. We also thank editor M. E. Contadakis and the other two anonymous referees for their helpful advices. We are also thankful to Anja Kesting, Anna Feist-Polner for their kind help.

Edited by: M. E. Contadakis

Reviewed by: two anonymous referees

\section{References}

Akinci, A., Galadini, F., Pantosti, D., Petersen, M., Malagnini, L., and Perkins, D.: Effect of Time Dependence on Probabilistic Seismic-Hazard Maps and Deaggregation for the Central Apennines, Italy, B. Seismol. Soc. Am., 99, 585-610, doi:10.1785/0120080053, 2009.

Benoit, M. H., Torpey, M., Liszewski, K., Levin, V., and Park, J.: $P$ and $S$ wave upper mantle seismic velocity structure beneath the northern Apennines: New evidence for the end of subduction, Geochem. Geophys. Geosys., 12, 1-19, doi:10.1029/2010GC003428, 2011.

Chiarabba, C., Amato, A., Anselmi, M., Baccheschi, P., Bianchi, I., Cattaneo, M., Cecere, G., Chiaraluce, L., Ciaccio, M. G., De Gori, P., De Luca, G., Di Bona, M., Di Stefano, R., Faenza, L., Govoni, A., Improta, L., Lucente, F. P., Marchetti, A., Margheriti, L., Mele, F., Michelini, A., Monachesi, G., Moretti, M., Pastori, M., Piana Agostinetti, N., Piccinini, D., Roselli, P., Seccia, D., and Valoroso, L.: The 2009 L'Aquila (central Italy) $\mathrm{M}_{W} 6.3$ earthquake: Main shock and aftershocks, Geophys. Res. Lett., 36, L18308, doi:10.1029/2009GL039627, 2009.
Cochran, E. S., Vidale, J. E., and Tanaka, S.: Earth tides can trigger shallow thrust fault earthquakes, Science, 306, 1164-1166, 2004.

Filizzola, C., Pergola, N., Pietrapertosa, C., and Tramutoli, V.: Robust satellite techniques for seismically active areas monitoring: a sensitivity analysis on September 7, 1999 Athens's earthquake, Phys. Chem. Earth, 29, 517-527, 2004.

Gorny, V. I., Salman, A. G., Tronin, A. A., and Shilin, B. B.: The Earth outgoing IR radiation as an indicator of seismic activity, $\mathrm{P}$. Acad. Sci. USSR, 301, 67-69, 1988.

Heaton, T. H.: Tidal triggering of earthquakes, Geophys. J. R. Astr. Soc., 2, 307-326, 1975.

Lisi, M., Filizzola, C., Genzano, N., Grimaldi, C. S. L., Lacava, T., Marchese, F., Mazzeo, G., Pergola, N., and Tramutoli, V.: A study on the Abruzzo 6 April 2009 earthquake by applying the RST approach to 15 years of AVHRR TIR observations, Nat. Hazards Earth Syst. Sci., 10, 395-406, doi:10.5194/nhess-10395-2010, 2010.

Lovallo, M., Marchese, F., Pergola, N., and Telesca, L.: Fisher information analysis of volcano-related advanced, very-highresolution radiometer (AVHRR) thermal products time series, Physica A, 384, 529-534, 2007.

Kalnay, E., Kanamitsu, M., Kistler, R., Collins, W., Deaven, D., Gandin, L., Iredell, M., Saha, S., White, G., Woollen, J., Zhu, Y., Leetmaa, A., Reynolds, B., Chelliah, M., Ebisuzaki, W., Higgins, W., Janowiak, J., Mo, K. C., Ropelewski, C., Wang, J., Jenne, R., and Joseph, D.: The NCEP/NCAR 40 years reanalysis project, B. Am. Meteor. Soc., 3, 437-471, 1996.

Ma, W., Ma, W., Zhao, H., and Li, H.: Temperature changing process of the Hokkaido (Japan) earthquake on 25 September 2003 Nat. Hazards Earth Syst. Sci., 8, 985-989, doi:10.5194/nhess-8985-2008, 2008.

Ma, W. M., Peng, W. L., Ma, W. Y., and Zhu, Y. X.: Tidal Force of Celestial Bodies and Temperature Change of the Three Microearthquakes in China, March 2009, Remote Sens. Inf., 1, 32-36, 2011 (in Chinese).

Ma, W. Y.: The Research on the Satellite Infrared Temperature Increase Abnormal of NCEP and the Astro-tidal-triggering to Forecast Short Impending Earthquake, Zhejiang University, Ph.D Dissertation, 2006 (in Chinese).

Ma, W. Y., Zhang, X., and Dai, X.: A preliminary study on the use of NCEP temperature images and addictive tectonic stress from astro-tidal triggering to forecast short-impending earthquakes, Earthquake Res. China, 21, 85-93, 2007.

Marchese, F., Pergola, N., and Telesca, L.: Investigating the temporal fluctuations in satellite advanced very high resolution radiometer thermal signals measured in the volcanic area of Etna (Italy), Fluct. Noise Lett., 6, 305-316, 2006.

Ouzounov, D. and Freund, F.: Mid-infrared emission prior to strong earthquakes analyzed by remote sensing data, Adv. Space Res., 33, 268-273, 2004.

Tanaka, S., Ohtake, M., and Sato, H.: Spatio-temporal variation of the tidal triggering effect on earthquake occurrence associated with the 1982 South Tonga earthquake of $\mathrm{M}_{w}$ 7.5, Geophys. Res. Lett., 29, 1756, doi:10.1029/2002GL015386, 2002.

Telesca, L.: A non-extensive approach in investigating the seismicity of L'Aquila area (central Italy), struck by the 6 April 2009 earthquake $\left(M_{L}=5.8\right)$. Terra Nova, 22, 87-93, 2010.

Tramutoli, V.: Robust Satellite Techniques (RST) for natural and environmental hazards monitoring and mitigation: ten years of 
successful applications, ISP MSRS 2005 Conference Proceedings, Beijing, China, 2005.

Tramutoli, V.: Robust Satellite Techniques (RST) for natural and environmental hazards monitoring and mitigation: theory and applications, Proceedings of MultiTemp 2007, 1-5, doi:10.1109/MULTITEMP.2007.4293057, 2007.

Tramutoli, V., Aliano, C., Corrado, R., Filizzola, C., Genzano, N., Lisi, M., Lanorte, V., Tsamalashvili, T., and Pergola, N.: Abrupt change in greenhouse gases emission rate as a possible genetic model of TIR anomalies observed from satellite in Earthquake active regions, Proceedings of 33rd International Symposium on Remote Sensing of Environment (ISRSE33), Stresa, Lago Maggiore, Italy, May 4-8, 2009.

Tronin, A. A.: Remote sensing and earthquakes: A Review, Physics and Chemistry of the Earth, Parts A/B/C, 31, 138-142, 2006.

USGS: availablat at: http://earthquake.usgs.gov/earthquakes/ eqinthenews/2009/us2009fcaf/\#summary

(last access: 9 March 2012), 2009.
Wu, L. X., Cui, C. Y., Geng, N. G., and Wang, J. Z.: Remote sensing rock mechanics (RSRM) and associated experimental studies, Int. J. Rock Mech. Min., 6, 879-888, 2000.

Wu, L. X., Liu, S. J., Wu, Y. H., and Wang, C. Y.: Precursors for rock fracturing and failure - part I: IRR image abnormalities, Int. J. Rock Mech. Min., 43, 473-482, 2006.

Wu, Q. P.: Gravitology and Solid Earth Tide, Beijing, Earthquake Publisher, 152-212, 1997 (in Chinese).

Yang, Y. Z. and Guo, G. M.: Studying the thermal anomaly before the Zhangbei earthquake with MTSAT and meteorological data, Int. J. Remote Sens., 31, 2783-2791, 2010.

Zhang, Y. S., Guo, X., and Zhong, M. J.: Wenchuan earthquake: Brightness temperature changes from satellite infrared information, Chinese Science Bulletin, Geophysics, 55, 1917-1924, 2010.

Zhu, J. S.: Computational methods in Seismology, Beijing, Earthquake Publisher, 181-189, 1988 (in Chinese). 